\title{
Research on Transient Overvoltage Suppression Measures for Photovoltaics Connected to the DC Sending End in the Smart Power System for Industry 4.0
}

\author{
Shuanbao Niu, ${ }^{1}$ Xianbo Ke, ${ }^{1}$ Qiang Shen $\mathbb{D}^{2},{ }^{2}$ Chao Huo, ${ }^{1}$ Ning Chen $\left(\mathbb{D},{ }^{3}\right.$ and Hua Li $\mathbb{D}^{2,4}$ \\ ${ }^{1}$ Northwest Branch of State Grid Corporation of China, Xi'an 710048, China \\ ${ }^{2}$ State Key Laboratory of Reliability and Intelligence of Electrical Equipment, Hebei University of Technology, \\ Tianjin 300130, China \\ ${ }^{3}$ China Electric Power Research Institute, Nanjing 210003, China \\ ${ }^{4}$ Key Laboratory of Electromagnetic Field and Electrical Apparatus Reliability of Hebei Province, Hebei University of Technology, \\ Tianjin 300130, China
}

Correspondence should be addressed to Hua Li; lihua69@hebut.edu.cn

Received 6 July 2020; Accepted 29 September 2020; Published 14 October 2020

Academic Editor: Ching-Hsin Wang

Copyright ( $\odot 2020$ Shuanbao Niu et al. This is an open access article distributed under the Creative Commons Attribution License, which permits unrestricted use, distribution, and reproduction in any medium, provided the original work is properly cited.

The development of smart power systems in Industry 4.0 will bring people better quality electrical energy. The photovoltaic power generation system in the smart grid for Industry 4.0 is also the focus of development. The rapid development of photovoltaic power generation systems will bring people cleaner and greener energy. However, it will cause the transient overvoltage phenomenon near the DC sending terminal when the large-scale photovoltaic plant is connected to the power grid, further bringing about a profound impact on the power grid and its security and stability. In this paper, it is proposed that the rise of transient overvoltage at the photovoltaic terminal is caused by three main factors including the reactive power surplus of DC commutation failure, the weak power grid at the sending terminal, and the control characteristics of the photovoltaic plant. Then, the coordinated control strategy of transient overvoltage is proposed, and the overvoltage control strategy of the DC transmission terminal and the photovoltaic power plant control strategy are, respectively, optimized. Finally, the influence parameters of overvoltage are analysed and the corresponding photovoltaic strategy is presented. The optimization results of photovoltaic parameters and the proposed strategies of photovoltaic power generation can effectively restrain the voltage or frequency fluctuation and power oscillation caused by HVDC commutation failure. This study promotes the development of the photovoltaic power generation system in the intelligent power system of industry 4.0.

\section{Introduction}

The intelligent power system for Industry 4.0 is built on the basis of a high-speed two-way communication network. Through advanced sensing and measurement technology, the goal of economic, safety, and reliability of the power grid is achieved $[1,2]$. The grid-connection security of the photovoltaic power generation system in the smart grid is still the focus of research [3-5]. At present, in the aspect of control strategy optimization of photovoltaic power generation access to the power system, most research studies focus on the reliability of the photovoltaic power plant itself.
However, few studies have considered the needs of the power grid, and there are very limited research studies on the optimization of the control strategy for large-scale photovoltaic power generation access to the DC send/receive end near-region power grid [6-9]. The installed capacity of new energy in the Qinghai Power Grid exceeds 50\% of the gross installed capacity in Qinghai Province, which has become the first installed power source in the province. Meanwhile, the Qinghai Power Grid possesses the provincial power source with the highest proportion of new energy in China $[10,11]$. Qinghai-Henan $\pm 800 \mathrm{kV}$ Ultra-High-Voltage Direct Current (UHVDC) project is the first clean energy DC 
transmission channel in China, which mainly utilizes new energy to generate electricity. The ratio of new energy installed in the Qinghai Power Grid at the DC transmission end accounts for up to $60 \%$. As large-scale wind power and photovoltaic power generation are directly boosted into the DC converter station bus, however, the conventional power supply in Qinghai is mainly the hydropower station located at the Yellow River, $300 \mathrm{~km}$ northeast of Qinghai. The Qingnan converter station and its supporting facilities for new energy are far apart, so it is difficult to effectively support the DC near area, resulting in the current situation of ultra-high proportion of power-electronic equipment access in the DC near area. There is fewer load in the DC near area of Qinghai-Henan. The new energy power station converges to boost and connects to the power grid at the sending end. The voltage of the new energy machine terminal is the highest point of the near area voltage during normal operation. The most serious failure at the end of the new energy machine is transient overvoltage attracted by the of DC commutation, and the basic positive sequence component often exceeds 1.3 p.u. The photovoltaic power station is a full-power-electronic grid-connected device, with an overvoltage withstand voltage limit of 1.3 p.u. lasting for $500 \mathrm{~ms}$. When the photovoltaic terminal voltage exceeds 1.3 p.u., instantaneous protection $(<50 \mu \mathrm{s})$ will be carried out immediately. Therefore, in order to retrain the transient overvoltage attracted by the commutation failure of DC system, the control strategy of photovoltaic power station needs to be optimized.

Renewable energy power stations are usually located in remote areas (such as Qinghai Province, China). However, after large-scale power generation, electricity energy needs to be transferred to the main load center [12]. The HighVoltage Direct Current (HVDC) transmission system has many advantages such as low transmission loss, large transmission capacity, and low cost. Therefore, the State Grid of China vigorously develops Ultra-High-Voltage (UHV) transmission technology which is suitable for long distances and large capacities and continuously upgrades the scale of UHVDC transmission [13-15]. In the UHVDC transmission system, DC commutation failure is a common fault, and HVDC commutation failure might produce voltage or frequency fluctuation and power oscillation [16-18]. In literature [19], it was shown that the occurrence of commutation fault will not only lead to the rapid decline of DC transmission power but also cause a serious power impact on the AC system. When the first commutation fault is not handled in time, it might cause continuous commutation fault in the inverter station, resulting in DC blocking and large-scale power failure. Literature [20] pointed out that continuous commutation faults (CFs) are serious faults in the HVDC transmission system of the converter station, which will cause power drop continuously and rapidly and threaten the stability of the AC system. Literature [21] points out that, in the multi-infeed HVDC system, the receiver of the AC system would also have the risk of multiple commutation failures after the first commutation failure. So as to figure out the matter of commutation failure of HVDC and cut down the frequency of commutation failure in high-voltage DC transmission of the line commutation converter (LCC-HVDC), literature [22] designed a coordinated control strategy between the DC chopper and LCC-HVDC, whose aim is to reduce the incidence of failures and improve failure recovery performance. To address the matter of transmission system instability caused by frequent commutation fault in the HVDC system, a fault division strategy based on fault current limiter is proposed in literature [23], which is proved to be an effective way to solve the commutation fault. However, the fuzzy control algorithm used in this paper is not perfect. Literature [24] proposed a predictive control strategy to reduce the risk of commutation failure, which is based on the DC value setting method of commutation failure prevention. The effectiveness and validity of the strategy is verified by simulation results. Literature [25] proposed a scheme of hybrid AC/DC relay and a thyristorcontrolled series compensator, which is based on the positive sequence component. The scheme can achieve comprehensive control and protection to solve the problem of commutation failure caused by DC fault.

In the aspect of fault ride-through, the optimization of the photovoltaic power generation control strategy is for the purpose of meeting the technical standards and maintaining the stability of photovoltaic power generation. A large number of studies have been conducted by equipment manufacturers, domestic and foreign research institutions, colleges, and universities [26-28]. Teodorescu and other scholars of Aalborg University in Denmark have studied the power control strategy of grid-connected converters in the case of power grid faults occurrence [29]. In literature [30], two adjustable coefficients are introduced to design the current reference expression model with continuous smooth switching control, the relationship between the amplitude of current harmonic distortion and active and reactive power oscillation and the regulation coefficient is deduced, and the coordination of current quality and power control is realized. The problems of reactive power and active power control are discussed in detail in literature [31], which provides a theoretical basis for the realization of power ridethrough. In literature [32], the safe crossing of the photovoltaic power generation system is realized by setting reference current and maximum power tracking control. In literature [33], a novel phase-locked tracking control is proposed, which can improve the synchronization and adaptive ability of signals under unbalanced faults. In literature [34], the salp swarm algorithm (SSA) is used. Lowvoltage ride-through (LVRT) is improved by optimizing photovoltaic controllers, and the proposed optimal control strategy is tested under various fault conditions. The results show that the strategy is better than the method of optimizing the PI controller. In reference [35], a combination method of whale optimization and squirrel search algorithm is proposed, which is used for power flow management of a grid-connected microgrid system with mixed renewable energy. Compared with the existing technology through simulation experiments, it can adapt to the requirements of the power grid much better. In literature [36], so as to deal with the problem that DC-link overvoltage and AC 
overcurrent may lead to grid inverter disconnection or even damage, a control method of single-stage photovoltaic power plants inverter is proposed to improve the performance of fault ride-through. Through the DC brake chopper circuit and current limiter, the scheme can realize the fault passing through the inverter without obvious overcompensation. In addition, in terms of small disturbances and oscillations in power systems with photovoltaic, it is pointed out that the system operation point is changed by fluctuating photovoltaic output in literature [37], and the grid-connected inverter has different control strategies compared with conventional units, which will change the damping of the system and affect the original electromechanical oscillation mode of the system. It will also bring about oscillations in the new frequency range. In literature [38], the existing planning models with optimization algorithm are evaluated so as to deal with the matter of small signal instability caused by the change of photovoltaic power supply or load, and it is proposed that the existing planning and design need to be improved in terms of design scale, layout mode, optimal timing, and so on. When photovoltaic generation is connected to the grid, there is a risk that the voltage stability of the hybrid microgrid will be destroyed due to the uncertainty of illumination, and a joint control strategy of local voltage and central voltage based on a twostage voltage control framework is proposed in literature [39], which can be used to alleviate the problem of voltage rise and reduce power loss.

An unreasonable photovoltaic power generation control strategy is not only not conducive to the removal of faults but also leads to chain off the grid and expands the scope of accidents [40]. In order to avoid the large-scale new energy generation chain off grid accident, the grid operation mode arrangement often reduces the DC transmission capacity or reduces the new energy generation on grid power in the near area. But, both of them are contrary to the original intention of increasing the proportion of new energy power generation and using UHVDC to transmit new energy for power generation. Nowadays, only a small number of domestic and foreign researchers study the control strategy and parameter transformation scheme of photovoltaic power stations connected to the actual power grid. Literature [41] proposed a distributed timing multiagent control strategy for frequency recovery and proportional reactive power distribution of the photovoltaic cell system with communication delay in the distributed microgrid, which can maintain charge balance even under intermittent photovoltaic generation and variable load. Literature [42] designed a gain scheduling wide-area damping controller to ensure the damping performance of the system under wide-area signal delays and proposed a linear parameter change model to describe photovoltaic power generation and load changes. This research can solve the adaptability of wide-area oscillation and random interval delay in the photovoltaic power generation system. Therefore, it is urgent to study deeply how to optimize the control strategy of photovoltaic power generation connected to a DC-sending near-area power grid [43].

As mentioned above, at this stage, there is an urgent need to consider the photovoltaic power station control strategy and parameter optimization empirical research in the actual power grid operation mode. This paper studies the transient overvoltage of photovoltaic power generation connected to UHVDC-sending end near area. Firstly, the mechanism of transient overvoltage is analysed, and it is proposed that the transient overvoltage at the end of photovoltaic, the most severe problem, is caused by three main factors: reactive power surplus of the accelerating effect of the control characteristics of the photovoltaic power plant and the weakness of the sending end of the power grid and DC commutation failure. On this basis, this paper puts forward the transient overvoltage suppression measures, optimized with regard to the DC control strategy (the source of the over voltage) and the side of the photovoltaic power station where the over voltage is the most serious, so as to effectively restrain the transient overvoltage at the DC sending end and avoid large-scale photovoltaic power generation chain off the grid. The main contributions are as follows:

(1) The coordinated control strategy of transient overvoltage was proposed, and the control objective of no overvoltage of AC bus at the DC sending end was realized

(2) To solve the problem of sudden disconnection of the photovoltaic power station during grid failure, the control strategy of the photovoltaic power station was optimized

(3) The factors affecting the overvoltage during commutation were analysed, and the corresponding photovoltaic strategy was proposed

This paper is organized as follows. Section 2 analyses overvoltage characteristics of photovoltaic grid-connected points during commutation failure. Section 3 introduces the UHVDC hierarchical connection mode. The transient overvoltage coordinated control strategy is discussed in Section 4. The influence parameters of photovoltaic gridconnected overvoltage during the commutation failure and corresponding photovoltaic power generation strategies are analysed in Section 5. Section 6 gives the conclusions.

\section{Analysis of Overvoltage Characteristics of Photovoltaic Grid-Connected Points during Commutation Failure}

2.1. DC Commutation Failure Leads to Rise of Reactive Surplus Voltage at the Sending End. In high-voltage DC systems, commutation failures are more common. If the cutoff angle is too small, the thyristor valve cannot fully restore the normal blocking ability. At this time, if a forward voltage is applied across the thyristor valve, the thyristor will continue to conduct. This process is called reverse commutation. The valve that should be turned off will continue to conduct, resulting in the commutation failure [24, 44].

The inverter valve on the inverter side is in off state most of the time, but the two ends of the inverter valve are subjected to reverse voltage. The commutation failure generally occurs on the inverter side. The main reason of commutation failure is AC system fault, which makes the voltage of commutation bus in the inverter side to decrease. 
In certain cases, commutation failure failures can be automatically restored. However, in case of continuous commutation failures, the converter valves of the thyristor will be locked, leading to the interruption of the DC transmission channel. In severe cases, commutation failures may occur simultaneously in multiple inverter stations, which may cause the grid to collapse. The photovoltaic power generation is merged into the $750 \mathrm{kV}$ bus at the DC transmission end through a 4-stage booster system. The UHVDC receiving terminal is connected to the AC power grid with different voltage levels.

For the UHVDC bipolar high-end valve, when the $500 \mathrm{kV}$ bus at the receiving end fails, the commutation failure will occur. The DC transmission power of the valves will be blocked. For the UHVDC bipolar low-end valve, when the $500 \mathrm{kV}$ bus at the receiving end fails, the commutation failure will not occur. The DC transmission power of the valves will not be blocked.

During the commutation failure, the DC current rises due to the $500 \mathrm{kV}$ bus fault at the inverter side. The triggering angle at the rectifier side increases rapidly to suppress the DC current overshoot. Because of the increase of the triggering angle at the rectifier side, the valve group consumes a large amount of reactive power, which leads to the decrease of DC bus voltage at the sending end. During the system recovery after the fault is cleared, with the recovery of $500 \mathrm{kV}$ bus voltage at the inverter side, the triggering angle gradually decreases to the normal operating value. During the recovery period, the reactive power consumed by the valve at the rectifier side group is lower than the normal operating value. The AC filter at the rectifier side generates lots of reactive surplus, which may cause the overvoltage of the AC bus at the sending end. Until the system returns to normal or DC blocking, the continuous commutation failure repeats this process.

\subsection{Control Strategy of the Photovoltaic Power Plant and} Reactive Power Compensation to Increase Transient Overvoltage. The reactive output of the reactive power compensation device of the photovoltaic power station is directly proportional to the square of the grid-connection voltage. As the DC bus voltage decreases, the reactive power of the compensation injection system will continually reduce during the period of DC commutation failure, which further reduces the voltage of the grid point of the photovoltaic power station. The photovoltaic power station has priority of the reactive power output. The active power continues to reduce, and the power flow of the power grid at the transmission end becomes lighter. With the rise of the DC bus voltage, the reactive surplus generated by the compensation device of the photovoltaic power station leads to a further rise of the grid-connected point voltage. Furthermore, the photovoltaic power station delays to exit from the low-voltage ride-through control strategy. The light power flow at the sending end caused by the unrecovered active power and the residual reactive power facilitates to increase the transient overvoltage. The process of fault ride-through control of the photovoltaic power station is shown in Figure 1.

Active power control is to simulate the photovoltaic inverter receiving and executing superior control commands and MPPT algorithm. When the photovoltaic inverter works at the maximum power tracking state, the MPPT algorithm obtains the DC voltage reference value of the photovoltaic inverter. When the photovoltaic inverter works in the active power control state (usually the active power command is less than the maximum output power), the DC control calculates the corresponding DC voltage reference value according to the active power command $[45,46]$. The relationship between the two is shown in Figure 2.

The active power control of the photovoltaic inverter receives instructions from the plant-level control system. The control model is shown in Figure 3.

The reactive power control module generally includes two modes [47]. One is constant power factor control, and the other is constant reactive power control. The constant reactive power control mode is used to describe that the photovoltaic inverter receives plant-level control commands and the inverter itself performs reactive power control. The constant power factor control is used to describe that the photovoltaic inverter does not receive plant-level reactive power commands but performs power factor control [48]. Figure 4 shows the reactive power control module.

The active power control strategy realizes the following functions. Firstly, the active power control strategy responds to plant-level active power control commands and increases (limited by irradiance) or decreases the active power. Secondly, the active control strategy works in the MPPT mode. The deviation between the DC voltage output and the DC reference voltage is input to the $\mathrm{DC}$ voltage controller to obtain the reference value of the active current.

The reactive power control strategy realizes the following functions. Firstly, the strategy responds to the plant-level reactive power control commands to control the power factor or reactive power of the inverter. Secondly, the reference value of reactive power or the power factor can also be a constant value. The inverter runs at unit power factor by default and the reactive output is 0 . The function of the current limiting strategy is to limit the reference values of active and reactive current to prevent overcurrent from damaging the equipment. According to different priorities, it can be divided into an active priority mode, reactive priority mode, and equal priority mode. The function of the fault ride-through control strategy is that the inverter switches to the fault ridethrough control mode to send or absorb reactive current to support the grid voltage when the power grid fails. The function of the current controller is to output high-frequency PWM pulse signals in response to the active or reactive current commands of the previous controller. The inverter bridge switch tube is driven. The protection control strategy refers to undervoltage protection, overvoltage protection, and over-underfrequency protection. The protection action value is set according to the standard requirements. 


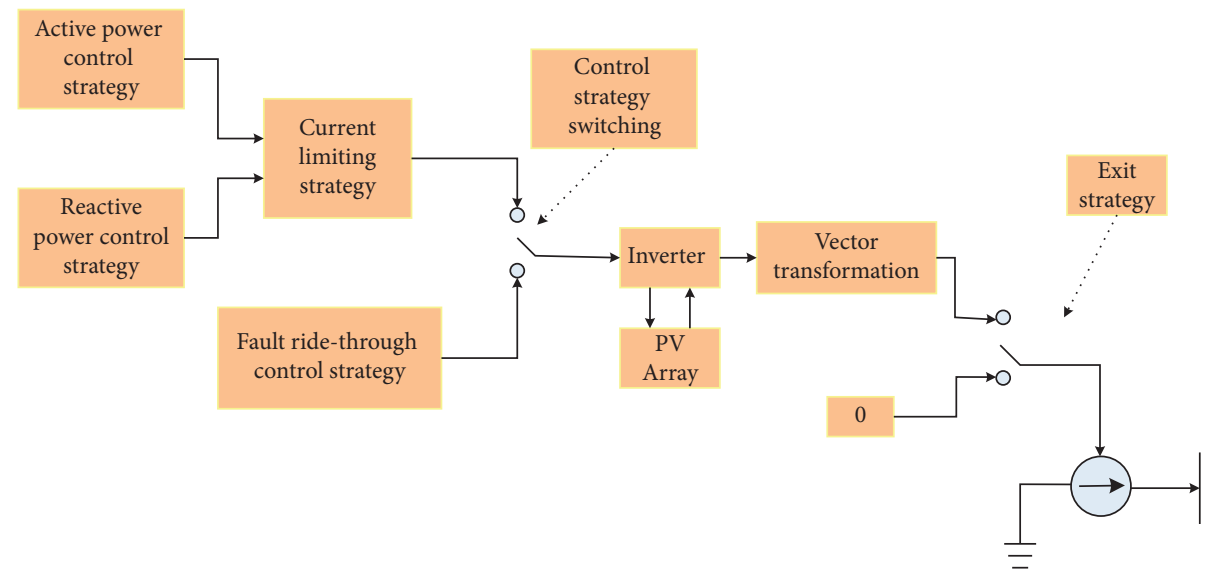

FIGURE 1: Fault ride-through control of photovoltaic power plants.

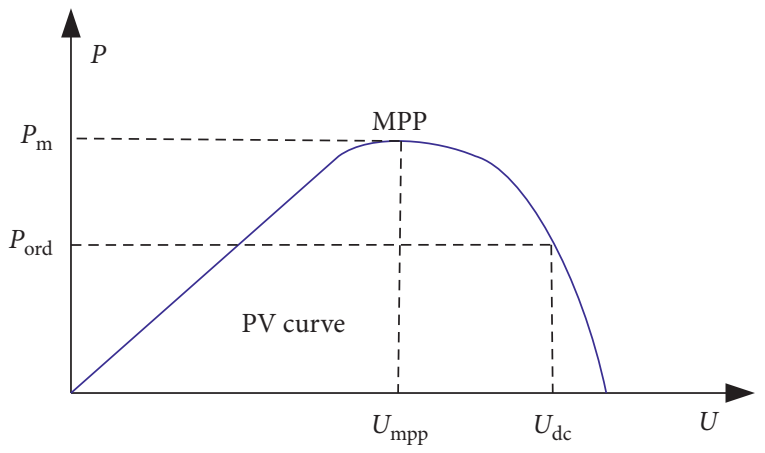

FIGURE 2: Control relationship between MPPT and active power.

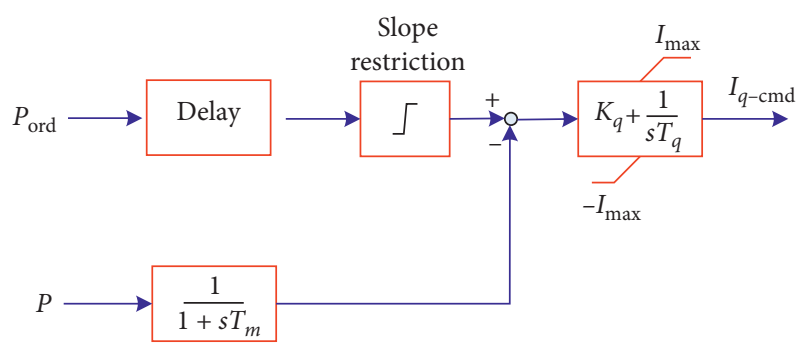

Figure 3: Active power control module of the photovoltaic inverter.

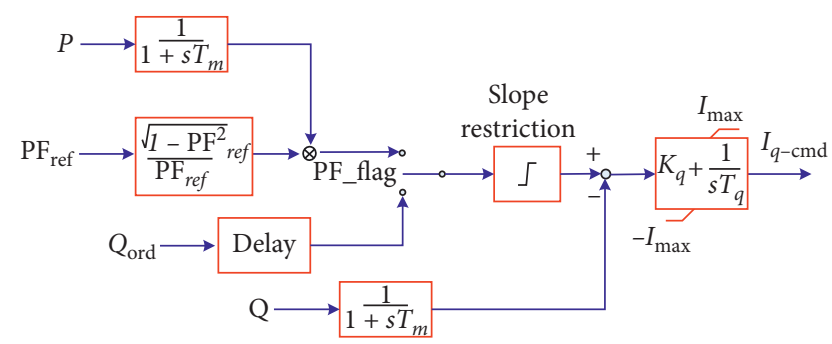

Figure 4: Reactive power control module.

\section{The Connection Mode of UHVDC}

3.1. UHVDC Single-Layer Connection Mode. Figure 5 presents the UHVDC single-layer connection mode. The AC side of the UHVDC converter station is directly connected to the $1000 \mathrm{kV}$ or $500 \mathrm{kV}$ power grid. The reactive power compensation device and AC filters are connected to the $1000 \mathrm{kV}$ or $500 \mathrm{kV}$ AC bus through the group switch.

The single-layer connection mode is suitable for the receiving-end grid in the absence of Ultra-High-Voltage Alternating Current (UHVAC) substations. The single-layer connection mode is directly connected to the local $500 \mathrm{kV}$ power grid, as close to the load center as possible meanwhile. The advantage of the single-layer connection method is that DC power is directly put into the large load center, which improves the transmission efficiency and reduces the system loss. The disadvantage is that the requirement of the strength of the grid frame, the receiving-end grid elimination capacity, and reactive power support capacity are higher. After the DC power is lost, the impact of the accident is greater, which will reduce the safety and stability of the receiving-end grid. Therefore, it is necessary to leave sufficient rotation reserve and fast reactive power support capacity of the local unit.

3.2. UHVDC Hierarchical Connection Mode. The UHVDC hierarchical connection mode is shown in Figure 6. The UHVDC high-end and low-end converter transformers are connected to $500 \mathrm{kV}$ and $1000 \mathrm{kV}$ power grids, respectively. The AC filters and reactive power compensation devices are also connected to $500 \mathrm{kV}$ and $1000 \mathrm{kV}$ AC buses $[49,50]$.

The advantage of the hierarchical connection mode is that the UHVAC power grid can be used to facilitate the configuration of DC power in a larger range, and there is no need to leave a large quantity of spinning reserves in the local power grid. Once the DC power is lost, it can take advantage of the UHVAC network to weaken the impact of the fault, which can make the system obtain greater antidisturbance capability and voltage support ability. It can give full play to the advantage of relatively low impedance of the UHVAC power grid system. The mode can reduce power grid operating losses further and obtain more economic benefits.

The disadvantages of the UHVDC hierarchical connection mode are as follows: the structure, operation characteristics, and control protection system of the receiving-end converter station are more complex. The 


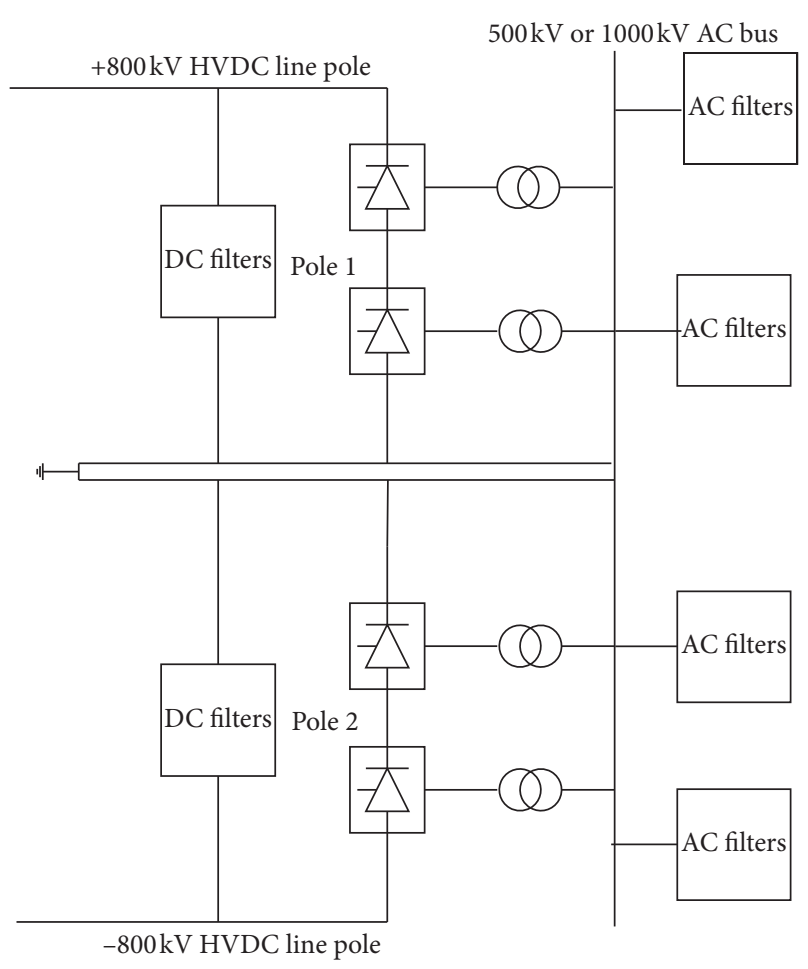

Figure 5: UHVDC single-layer connection mode to AC.

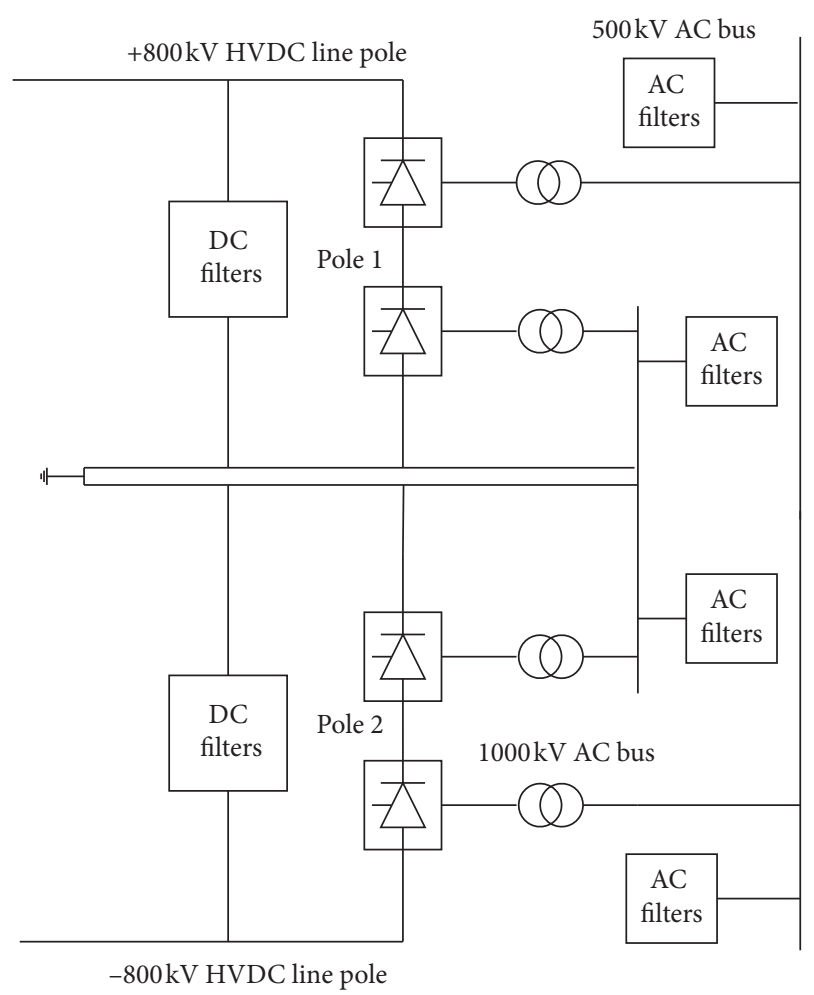

FIgURE 6: UHVDC hierarchical connection mode to AC.

receiving-end power grid must develop the UHVAC grid, otherwise the hierarchical connection of DC cannot be achieved, and the short-circuit current level of the system is higher.

\section{The Transient Overvoltage Coordinated Control Strategy}

Transient voltage stability is an important part of power system safety and stability analysis. In recent years, with the expansion of the power system interconnection scale and the increase of DC transmission capacity, the stability problem of the power system has become increasingly prominent, especially when large DC power disturbance happens (such as DC block and commutation failure). The occurrence of transient overvoltage will cause a large impact on the transmission equipment.

The proposed overvoltage coordinated control strategy for grid-connection point of photovoltaic station takes the reactive power surplus of the DC filter of the sending end and the reactive power compensation device on the gridconnection point as the control objectives. The overvoltage strategy of the UHVDC sending end and the control strategy of the photovoltaic station in the hierarchical connection mode are optimized to reduce the risk of high-voltage offgrid of photovoltaic station units.

4.1. Optimization of the Overvoltage Control Strategy for the $D C$ Sending End. The calculation formula for the exchange of reactive power between the rectifier side converter and the AC system is shown as follows:

$$
Q_{\mathrm{dc}}=Q_{\mathrm{f}}+Q_{\mathrm{ac}},
$$

where $Q_{\mathrm{dc}}$ is the reactive power consumed by the converter, $Q_{\mathrm{ac}}$ is the reactive power provided by the sending end of the $A C$ grid, and $Q_{f}$ is the reactive power provided by AC filters. The transmission system adopts the constant reactive power control mode. By adjusting the tap of converter transformer and the trigger angle of the rectifier side, $Q_{\mathrm{ac}}$ can be kept within a relatively small dead zone value. $Q_{\mathrm{dc}}$ approximately equals to $Q_{\mathrm{f}}$.

According to the quasi-steady-state equation of the DC transmission system,

$$
\left\{\begin{array}{l}
Q_{\mathrm{dc}}=P \tan \phi, \\
\cos \phi=\frac{1}{2}[\cos \alpha+\cos (\alpha+\mu)], \\
U_{\mathrm{d}}=U_{\mathrm{di} 0} \cos \phi \\
P=U_{\mathrm{d}} I_{\mathrm{d}},
\end{array}\right.
$$

where $P$ is the DC power, $\alpha$ is the trigger angle for the rectifier side, $\phi$ is the power factor angle of the converter, and $\mu$ is the overlap angle. $U_{\mathrm{di} 0}$ is the ideal no-load DC voltage of the inverter, and $I_{\mathrm{d}}$ is the direct current. The expression after mathematical transformation of formula (2) is as follows:

$$
\mathrm{Q}_{\mathrm{dc}}=\frac{U_{\mathrm{di0}}[2(\pi / 180)+\sin 2 \alpha-\sin 2(\alpha+\mu)]}{4[\cos \alpha-\cos (\alpha+\mu)]} I_{\mathrm{d}} .
$$

Taking partial derivative of $Q_{\mathrm{dc}}$ with respect to $I_{\mathrm{d}}$, 


$$
\frac{\partial Q_{\mathrm{dc}}}{\partial I_{\mathrm{d}}}=U_{\mathrm{di} 0} \frac{[\cos 2 \alpha-\cos 2(\alpha+\mu)]}{2[\sin (\alpha+\mu)-\sin \alpha]}>0 .
$$

From formula (4), $Q_{\mathrm{dc}}$ is positively correlated with the DC current $I_{\mathrm{d}}$. When the DC system of the hierarchical connection mode has failed to change phase and the DC delivery power of the inverter side faulty grid-connected converter is blocked, the converter connected to the nonfault grid on the inverter side can still transmit part of the DC power. By modifying the DC current command value of the converter, the reactive power consumption of the converter is increased, thereby reducing the reactive power input to the system of the reactive power compensation device and suppressing the overvoltage of the DC transmission end grid.

The proposed logic strategy for overvoltage optimization of the DC sending end is shown in Figure 7, and the dotted box shows the overvoltage suppression strategy of the sending bus. In the picture, $U_{\mathrm{dREC}}$ is the DC bus voltage at the rectifier side, $I_{\mathrm{ORD}}$ is the current command generated by the pole control, $I_{\mathrm{d}}$ is the DC bus current, and AIpha_ORD is trigger angle command on the rectifier side. In normal conditions, the output of the rectifier side voltage regulator acts as the lower limit of the current regulator.

The sending end bus voltage detection module is used to determine and quantify the condition of the DC sending end AC system. $U_{\mathrm{HV}}$ is set as fault state variable. When the bus voltage of the sending end is more than $1.1 \mathrm{pu}, U_{\mathrm{HV}}$ is set to 1. When the bus voltage of sending end is less than $1.1 \mathrm{pu}$, $U_{\mathrm{HV}}$ is set to 0 . When $U_{\mathrm{HV}}$ is 1 , the reactive current command control module is started. According to formula (3), the DC current command value during the overvoltage period can be calculated. When the commutation failure occurs in the hierarchical connection DC system, the valve group connected to the nonfaulted power grid is used to transmit DC power in a short time to avoid overvoltage in the $\mathrm{AC}$ bus of the DC sending end.

4.2. Control Optimization Strategy of the Photovoltaic Station. The access of large-scale photovoltaic stations will have a profound impact on the power grid. When the photovoltaic power station is suddenly disconnected from the grid, it will further deteriorate the operating state of the power grid and bring more serious consequences. Therefore, the control strategy of the photovoltaic power station needs to be optimized.

The factors contributing to the transient overvoltage of the photovoltaic generator include the characteristics of the power station reactive power compensation equipment and the control strategy of the photovoltaic power station. Therefore, the optimization strategy of the photovoltaic station includes two parts.

First of all, the reactive power output of the reactive power compensation equipment of the photovoltaic station is reduced. The reactive power loss of the transmitted power is compensated by the own reactive power of the photovoltaic inverter, that is, the reactive power components of the photovoltaic station are reduced and the failure reactive surplus is further reduced in the process of commutation. Second, the control logic of the fault ride-through of the photovoltaic power station is optimized to reduce the impact of power flow during the fault process.

When the photovoltaic inverter is in the fault ridethrough state, the inverter mode is switched to the fault ride-through mode, and the reactive current is output preferentially. The active power output is reduced, and the power imbalance phenomenon occurs on both sides of the DC bus capacitor, resulting in the increase of DC bus voltage. The increase of the DC voltage causes the output power of the photovoltaic array to decrease, which naturally completes the switch from the normal operating state to the fault state.

The fault ride-through reactive current of the photovoltaic inverter is related to the reactive current before the fault and the sag degree of voltage. The active current of the fault ride-through is related to the control strategy, reactive current during the fault, and active current before the fault.

The fault ride-through control logic of the photovoltaic station includes three processes: low-voltage ride-through control, low-voltage recovery control, and high-voltage ridethrough control. The division of the three processes is based on the photovoltaic terminal voltage $U_{\text {term. }}$ When $U_{\text {term }}$ is lower than the low-voltage crossing threshold $U_{\mathrm{LV}}$, it is lowvoltage ride-through control; when $U_{\text {term }}$ recovers above $U_{\mathrm{LV}}$ and does not reach the high-voltage crossing control threshold $U_{\mathrm{HV}}$, it is low-voltage ride-through restoration control; and when $U_{\text {term }}$ is higher than $U_{\mathrm{HV}}$, it is highvoltage ride-through control.

Low-voltage ride-through technology of photovoltaic stations means that when the voltage of the grid-connection point of the photovoltaic station is reduced due to grid failure or disturbance, the photovoltaic station can be continuously connected to the grid within a certain range. The mathematical model of the low-voltage ride-through and recovery control process is shown as follows:

$$
\begin{aligned}
& \left\{\begin{array}{l}
I_{\mathrm{p}}=I_{\mathrm{p}_{-} \mathrm{LV}}, \\
I_{\mathrm{q}}=K_{\mathrm{qV} \_\mathrm{LV}}\left(U_{\mathrm{LV}}-U_{\text {term }}\right),
\end{array}\right. \\
& I_{\mathrm{p}}(t)=I_{\mathrm{p}}(t-\Delta t)+K_{\mathrm{dp}} \cdot \Delta t,
\end{aligned}
$$

where $U_{\mathrm{LV}}$ is the threshold voltage of the inverter during low-voltage ride-through, $K_{\mathrm{qv} \_\mathrm{LV}}$ is the reactive current support coefficient of the inverter during low-voltage ridethrough, $I_{\mathrm{p} \_L V}$ is the active current reference value of the inverter during low-voltage ride-through, $K_{\mathrm{dp}}$ is the slope of active current recovery after the fault is eliminated, $t$ is the simulation time, and $\Delta t$ is the simulation step.

High-voltage ride-through of the photovoltaic station means that when the grid-connection point of the photovoltaic station rises due to an accident or disturbance in the power system, the photovoltaic station can ensure continuous operation without disconnection from the grid within a certain voltage increase range and time interval. The mathematical model of high-voltage ride-through of photovoltaic stations is shown below. 


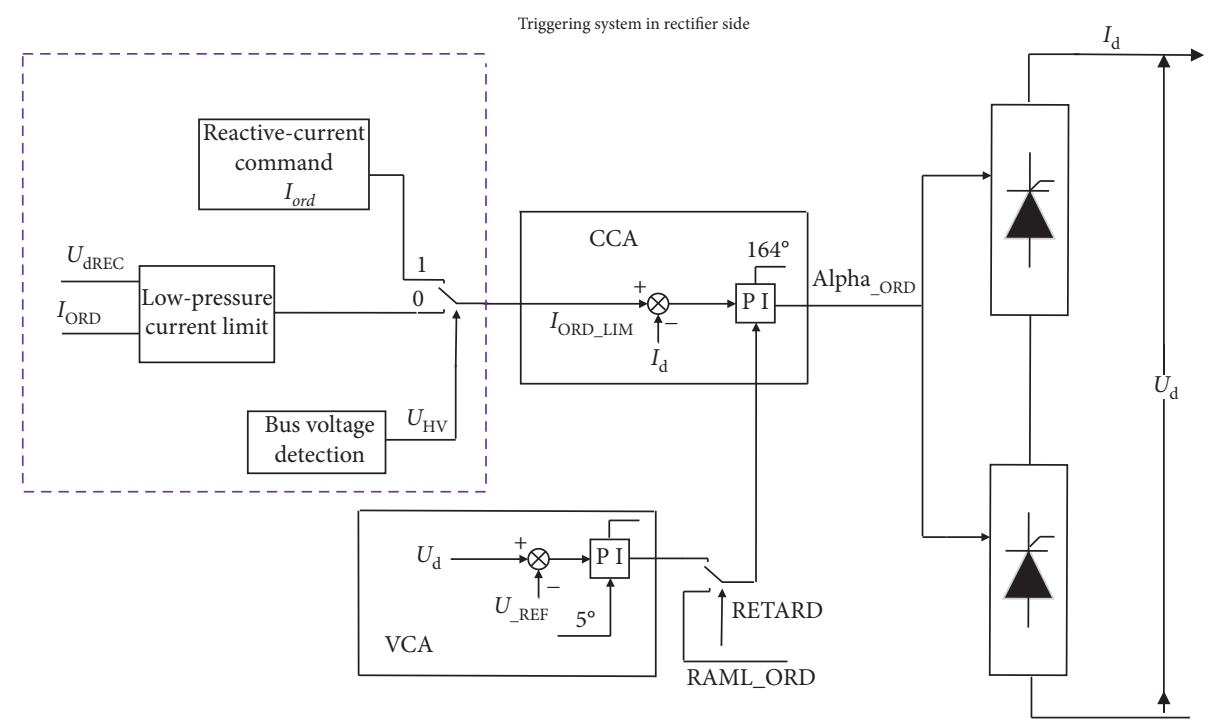

Figure 7: Block diagram of the rectifier side valve trigger control system.

$$
\left\{\begin{array}{l}
I_{\mathrm{p}}=I_{\mathrm{p} \_\mathrm{HV}}, \\
I_{\mathrm{q}}=K_{\mathrm{qV} \_\mathrm{HV}}\left(U_{\mathrm{HV}}-U_{\text {term }}\right),
\end{array}\right.
$$

where $U_{\mathrm{HV}}$ is the threshold voltage for the inverter during high-voltage ride-through; $K_{\mathrm{qv} \_\mathrm{HV}}$ is the reactive current support coefficient of the inverter during high-voltage ridethrough; $I_{\mathrm{p}_{-} \mathrm{HV}}$ is the active current reference value of the inverter during high-voltage ride-through.

The PV fault ride-through control strategy adopts the measure of reactive power priority to reduce the voltage shock during the commutation failure. At the same time, a high level of active current must be maintained to reduce the influence of power flow during the fault. The specific optimization strategies are shown in Table 1.

\section{Analysis of the Influence Parameters of Photovoltaic Grid-Connected Overvoltage during the Commutation Failure and Corresponding Photovoltaic Power Generation Strategies}

When the terminal voltage is lower than the low-voltage ride-through threshold $(0.9 \mathrm{pu})$, the unit will give priority to the reactive power and reduce the active power to support the grid voltage. As the grid-connected technical standard has not clearly proposed the reactive current support range and active power control ability, the control logic of photovoltaic units is not the same. Table 2 shows the voltage range of different grid-connection points of photovoltaic power plants.

When the power grid changes from low voltage to overvoltage rapidly, the change of reactive and active power of photovoltaic power generation will lag due to the influence of voltage measurement and control delay, causing the photovoltaic unit to still send out reactive power during the overvoltage period. Meanwhile, the active power is in the
TABLE 1: Control parameter optimization value.

\begin{tabular}{lc}
\hline Control parameters & Optimized value \\
\hline$U_{\mathrm{LV}}$ & $0.9 \mathrm{p} . \mathrm{u}$. \\
$K_{\mathrm{qv} \_\mathrm{LV}}$ & $1.5 \mathrm{p} . \mathrm{u}$. \\
$I_{\mathrm{p} \_\mathrm{LV}}$ & $I_{\mathrm{p} 0}^{*}$ \\
$K_{\mathrm{dp}}$ & $3.0 \mathrm{p} . \mathrm{u} . / \mathrm{s}$ \\
$U_{\mathrm{HV}}$ & $1.1 \mathrm{p} . \mathrm{u}$. \\
$K_{\mathrm{qv} \_\mathrm{HV}}$ & $1.5 \mathrm{p} . \mathrm{u}$. \\
$I_{\mathrm{p} \_\mathrm{HV}}$ & $P_{0}^{*} / U_{\text {term }}$ \\
\hline
\end{tabular}

$I_{\mathrm{p} 0}^{*}$ is the active current of the photovoltaic station before the failure of DC commutation; $P_{0}^{*}$ is the active power of photovoltaic station before DC commutation failure.

TABLE 2: Operating requirements of voltage range of photovoltaic power plants at different grid-connection points.

\begin{tabular}{lc}
\hline Voltage range & Operating requirements \\
\hline$U_{T}<0.9 \mathrm{pu}$ & Meet low-voltage ride-through \\
$0.9 \mathrm{pu} \leq U_{T} \leq 1.1 \mathrm{pu}$ & requirements \\
$1.1 \mathrm{pu}<U_{T}<1.2 \mathrm{pu}$ & Normal operation \\
$1.2 \mathrm{pu} \leq U_{T} \leq 1.3 \mathrm{pu}$ & Continuous operation for at least $10 \mathrm{~s}$ \\
\hline
\end{tabular}

state of low output, resulting in further increase of system overvoltage in the photovoltaic power plant.

Next, the effects of photovoltaic low-voltage ridethrough active current, photovoltaic low-voltage ridethrough reactive coefficient, and photovoltaic response speed on the sending end overvoltage are analysed. When commutation fails, the effect of reactive power support on overvoltage is shown in Figure 8.

As shown in Figure 8, the influence of reactive power support for blocking instantaneous overvoltage is obvious during low-voltage ride-through. When the reactive coefficient is 2.5 , the highest point overvoltage is 1.346 . When the reactive coefficient is 2.0 , the highest point overvoltage is 1.34. When the reactive coefficient is 1.5 , the highest point 


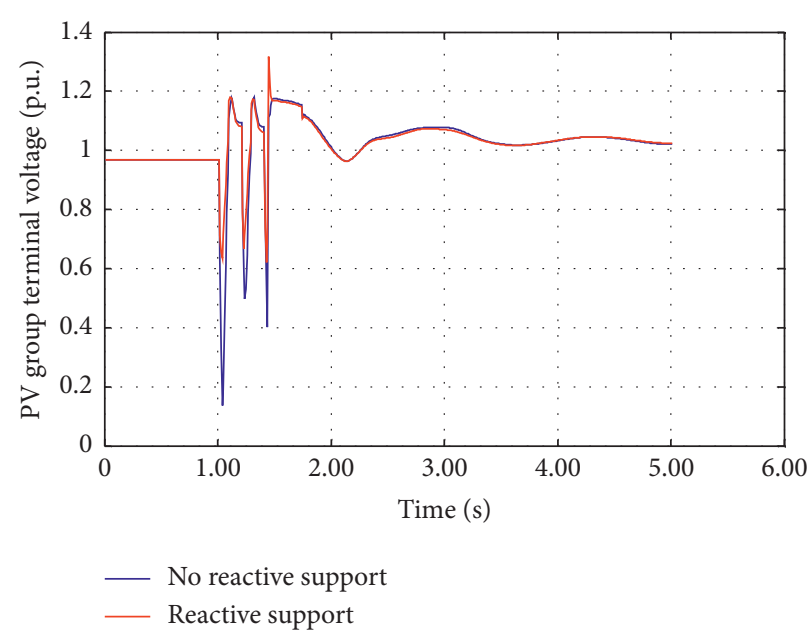

(a)

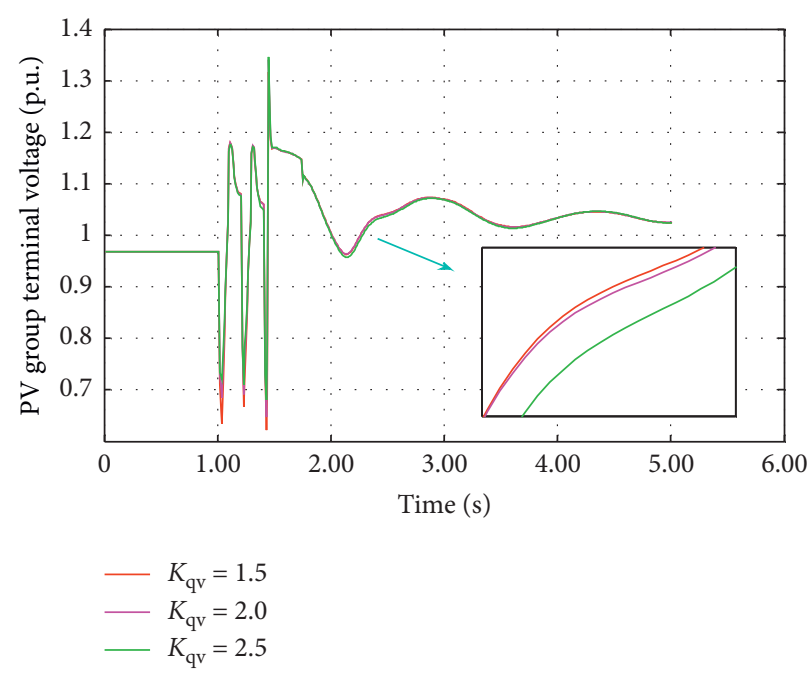

(b)

FIGURE 8: Effect of reactive power support on overvoltage. (a) Reactive support. (b) Influence of different reactive power coefficients on overvoltage.

overvoltage is 1.316. By comparison, it is found that the reactive power support coefficient has a little effect on the voltage sag of the commutation failure and the blocking instantaneous overvoltage, and the effect is not obvious. In response to this situation, the photovoltaic power generation strategy is to generate active power by remaining capacity and to generate reactive power during low-voltage ridethrough. The reactive power is absorbed during high-voltage ride-through. The reactive power coefficient is 1.5. The lowvoltage ride-through reactive power support coefficient was adjusted through the photovoltaic power generation strategy, and then, the voltage drop degree of the commutation failure and the transient overvoltage of the blocking were adjusted.

In the absence of the reactive power absorption strategy during photovoltaic high-voltage ride-through, the impact of active current on overvoltage is shown in Figure 9.

As shown in Figure 9, when the active coefficient is 0.1, the highest point overvoltage is 1.437 . When the active coefficient is 0.3 , the highest point overvoltage is 1.427 . When the active coefficient is 0.7 , the highest point overvoltage is 1.344 . When the active coefficient is 1.0 , the highest point overvoltage is 1.321 . The active current during the low-voltage ride-through period has a greater impact on the voltage characteristics of the commutation failure blocking without the reactive power absorption strategy during high-voltage ride-through. The voltage rise of the first two commutation failures becomes higher when the active current is relatively small during low-voltage ride-through. In view of this situation, the photovoltaic power generation strategy is to generate reactive power during low-voltage ride-through. The reactive coefficient is 1.5 . The active current coefficient changes with the recovery rate of 0.5 . The reactive power is not absorbed during high-voltage ridethrough. By adjusting the photovoltaic power generation strategy, the influence of active current on the voltage characteristics of commutation failure blocking can be reduced.

In the case of setting the photovoltaic high-voltage ridethrough absorption reactive power strategy, the effect of lowvoltage ride-through active current on overvoltage is shown in Figure 10.

As shown in Figure 10, in the case of setting the reactive power absorption strategy during photovoltaic high-voltage ride-through, the highest point overvoltage changes from the commutation failure process to the blocking moment. Different active values have little effect on the system overvoltage. Both the reactive power absorption during the high-voltage ridethrough period and the high active power value during the lowvoltage ride-through period can slow down the transient overvoltage during DC faults. There is a nonmonotonic relationship between the active current and the voltage. The smaller the photovoltaic active current is, the higher the low voltage during commutation failure is. The corresponding fault reactive current is small. During the fault, the overall power flow becomes lighter and the voltage rises. At the instant of DC blocking, the excessive active current will cause the reactive current during the low-voltage period to increase the instantaneous overvoltage. If the active current is too light, it will cause the current of the entire network to be lighter and the voltage to rise. In view of this situation, the photovoltaic power generation strategy is to generate reactive power during low-voltage ridethrough, and the reactive coefficient is 1.5 . The recovery rate of active current during low-voltage ride-through is 3.0. The reactive power is absorbed during high-voltage ride-through, and the coefficient is 1.5 . In the case of the PV high ride-through voltage reactive power strategy, different low-voltage ridethrough active power values have little impact on the system overvoltage. The transient overvoltage during DC fault can be reduced both in the high-voltage ride-through period and the low-voltage ride-through period after adjusting the photovoltaic power generation strategy. 


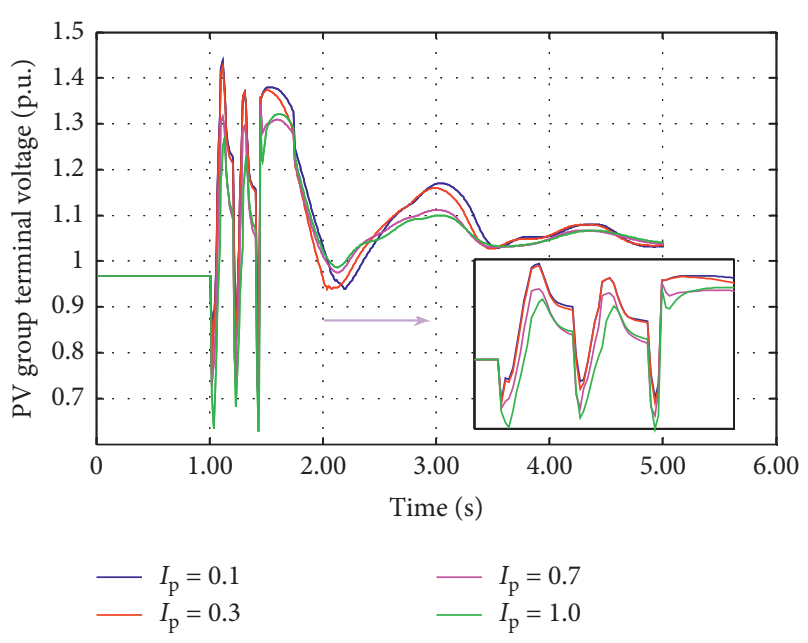

FIGURE 9: The effect of the active coefficient on overvoltage without the high-voltage ride-through reactive power absorption strategy.

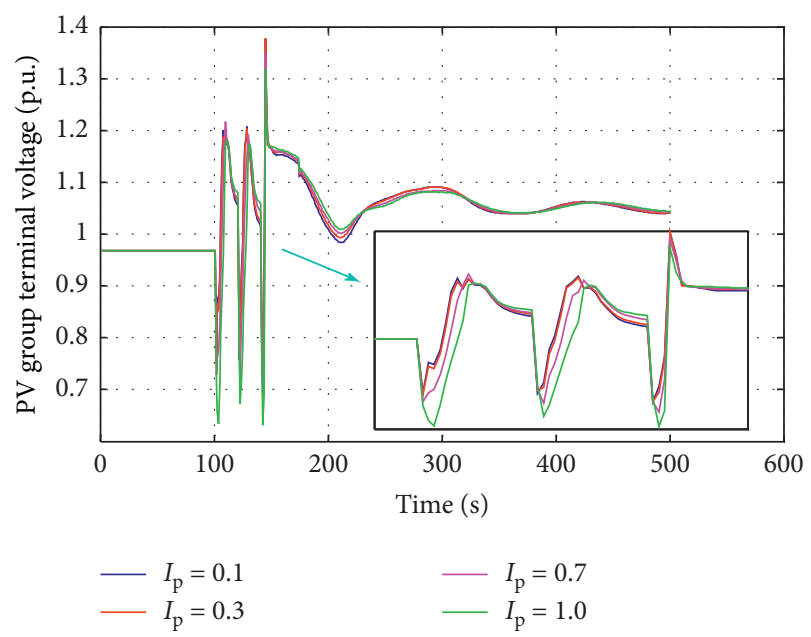

FIGURE 10: The effect of the active coefficient on overvoltage with the high-voltage ride-through reactive power absorption strategy.

The effects of different photovoltaic response speeds on overvoltage are shown in Figure 11.

As shown in Figure 11, the peak overvoltage peak of the DC blocking instant can be significantly reduced by increasing the photovoltaic response speed, but it is more difficult to accelerate the response speed of the photovoltaic inverter. In view of this situation, the photovoltaic power generation strategy is to generate reactive power during low-voltage ride-through, and the reactive power coefficient is 1.5. The active current coefficient is 1.0, and the recovery rate of active current during low-voltage ride-through is 3.0. The reactive power is absorbed during high-voltage ride-through. The response speed of photovoltaic inverter can be improved by the photovoltaic power generation strategy, and the peak value of instantaneous overvoltage can be reduced in the further DC blocking.

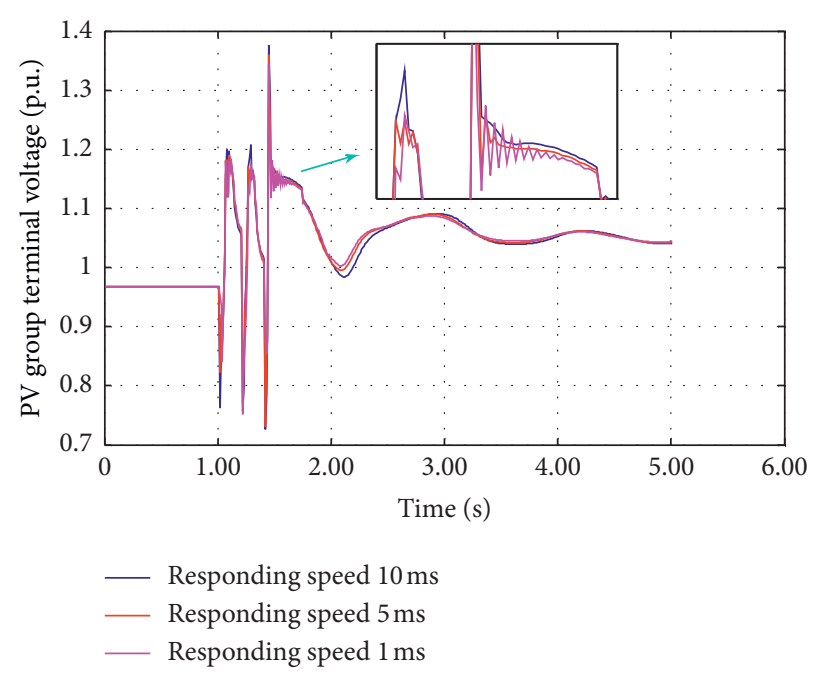

Figure 11: The effect of photovoltaic response speed on overvoltage.

\section{Conclusions}

The development and application of the intelligent power system in industry 4.0 will improve user experience and energy efficiency. The development and utilization of the photovoltaic power generation system in smart grid for Industry 4.0 is also a research hotspot. The photovoltaic power generation system can bring people more clean and green power. The HVDC system has the advantages of large transmission capacity, low cost, and low transmission loss. Therefore, China's State Grid vigorously develops UHV transmission technology which is suitable for long distance and large capacity and continuously upgrades the scale of UHVDC transmission. DC commutation failure is a common fault in the UHVDC transmission system, but HVDC commutation failure may cause voltage or frequency fluctuation and power oscillation. At the same time, the unreasonable photovoltaic power generation control strategy will lead to the chain offgrid. By reducing the DC transmission capacity or reducing the new energy generation on grid power in the near area, the grid can effectively avoid the large-scale new energy generation chain offgrid. In this paper, the temporary overvoltage of large-scale photovoltaic power generation connected to the near area of the UHVDC sending end is studied, and the coordination control strategy of temporary overvoltage and the control strategy of the photovoltaic power station are proposed. The main contributions of this paper are as follows:

(1) By analyzing the mechanism of generating temporary overvoltage, it is proposed that the reactive power surplus of DC commutation failure, the weakness of the sending end of the power grid, and the accelerating effect of the control characteristics of the photovoltaic power plant collectively cause the most severe temporary overvoltage at the end of photovoltaic. 
(2) In this paper, a transient overvoltage coordinated control strategy is proposed. In case of commutation failure of the DC system with a hierarchical connection mode, the valve group connected to a nonfault grid is used to transmit DC power for a short time to increase the reactive power consumption of converter, so as to achieve the control goal of no overvoltage of $\mathrm{AC}$ bus at the DC sending end.

(3) When the power grid failure happens, the sudden disconnection of the photovoltaic power station will further worsen the operation state of the power grid. In this paper, the control strategy of the photovoltaic power station is optimized, and the optimal value of the control parameters is given.

(4) The influence parameters of photovoltaic parallel network overvoltage during commutation failure are analysed, and the corresponding photovoltaic strategy is put forward. In view of the influence of reactive power coefficient on overvoltage, a photovoltaic power generation strategy is proposed, in which reactive power is generated during low-voltage ride-through and active power is generated by residual capacity. Reactive power is absorbed during high-voltage ride-through, and the reactive power coefficient is 1.5. In view of the influence of the active power coefficient on overvoltage, a photovoltaic power generation strategy is proposed, in which reactive power is generated during low-voltage ride-through, and the reactive power coefficient is 1.5. The active current coefficient is variable, and the recovery rate of active current during low-voltage ridethrough is 0.5 . Reactive power is not absorbed during high-voltage ride-through. In view of the influence of response speed of photovoltaic power generation on overvoltage, a photovoltaic power generation strategy is proposed, in which reactive power is generated during low-voltage ride-through, and the coefficient is 1.5 . The active current coefficient is 1.0 , and the recovery rate of active current of low-voltage ride-through is 3.0. Reactive power is absorbed during high-voltage ridethrough, and the coefficient is 1.5 .

(5) This study has a positive impact on the development of the smart grid and the development and utilization of new energy for Industry 4.0.

The large-scale new energy collection system has a transient overvoltage problem under AC/DC fault, which has a great impact on the safety and stability of UHVDC transmission of clean energy. Therefore, it is necessary to study and put forward the suppression measures of photovoltaic transient overvoltage at the DC side of the power grid in terms of power system stability. Due to the measurement, control, output filtering, and other links, there is a certain delay in the active and reactive power response of power-electronic equipment in the process of rapid voltage change of the new energy system. The access of new energy will increase the operation risk of equipment and the system during the process of power grid fault recovery. The future research work can be combined with the specific DC sending end access system conditions and distributed small capacity condenser.

\section{Data Availability}

The analytical data used to support the findings of this study are included within the article.

\section{Conflicts of Interest}

The authors declared no potential conflicts of interest with respect to the research, authorship, and/or publication of this article.

\section{Acknowledgments}

This work was supported by the Science and Technology Project of State Grid Corporation of China (Project no. 5442NY190024).

\section{References}

[1] F. M. Ran, D. C. Gao, X. Zhang et al., "A virtual sensor based self-adjusting control for HVAC fast demand response in commercial buildings towards smart grid applications," Applied Energy, vol. 269, 2020.

[2] G. Hafeez, K. S. Alimgeer, and I. Khan, "Electric load forecasting based on deep learning and optimized by heuristic algorithm in smart grid," Applied Energy, vol. 269, 2020.

[3] Z. F. Liu, L. L. Li, M. L. Tseng et al., "Prediction short-term photovoltaic power using improved chicken swarm optimizer - extreme learning machine model," Journal of Cleaner Production, vol. 248, no. 14, 2020.

[4] A. F. D. Silva, S. P. Pimentel, E. G. Marra et al., "Design of a robust $\mathrm{H}$-infinity current controller for grid-connected photovoltaic systems based on cascaded multilevel inverter," IET Renewable Power Generation, vol. 14, no. 5, pp. 713-724, 2020.

[5] L.-L. Li, Y.-B. Chang, M.-L. Tseng, J.-Q. Liu, and M. K. Lim, "Wind power prediction using a novel model on wavelet decomposition-support vector machines-improved atomic search algorithm," Journal of Cleaner Production, vol. 270, Article ID 121817, 2020.

[6] R. P. Aguilera, P. Acuna, Y. Yu et al., "Predictive control of cascaded H-bridge converters under unbalanced power generation," IEEE Transactions on Industrial Electronics, vol. 64, no. 1, pp. 4-13, 2017.

[7] N. I. Ahmad, M. Z. A. Ab-Kadir, M. Izadi et al., "Lightning protection on photovoltaic systems: a review on current and recommended practices," Renewable and Sustainable Energy Reviews, vol. 82, pp. 1611-1619, 2018.

[8] A. Abusorrah, M. M. Al-Hindawi, Y. Al-Turki et al., "Stability of a boost converter fed from photovoltaic source," Solar Energy, vol. 98, pp. 458-471, 2013.

[9] L. L. Li, X. Zhao, M. L. Tseng et al., "Short-term wind power forecasting based on support vector machine with improved dragonfly algorithm," Journal of Cleaner Production, vol. 242, no. $12,2020$.

[10] C. B. Li, Y. Q. Liu, and S. K. Li, "Risk evaluation of QinghaiTibet power grid interconnection project for sustainability," Sustainability, vol. 8, no. 1, 2016. 
[11] Y. Yang, C. Lian, C. Ma et al., "Research on energy storage optimization for large-scale PV power stations under given long-distance delivery mode," Energies, vol. 13, no. 1, 2020.

[12] M. Arif, F. Ahmad, R. Kashyap et al., "Evaluation of EHV and $\mathrm{AC} / \mathrm{DC}$ technologies for integration of large-scale renewable generation in Saudi Arabian network," IET Generation, Transmission \& Distribution, vol. 13, no. 4, pp. 575-581, 2019.

[13] L. Sun, H. B. Liu, and C. L. Ma, "AC tie-line power oscillation mechanism and peak value calculation for a two-area AC/DC parallel interconnected power system caused by LCC-HVDC commutation failures," Energies, vol. 13, no. 5, 2020.

[14] Y. Miao and H. Cheng, "An optimal reactive power control strategy for UHVAC/DC hybrid system in east China grid," IEEE Transactions on Smart Grid, vol. 7, no. 1, pp. 392-399, 2016.

[15] R. Dai, G. Liu, and X. Zhang, "Transmission technologies and implementations: building a stronger, smarter power grid in China," IEEE Power and Energy Magazine, vol. 18, no. 2, pp. 53-59, 2020.

[16] Y. P. Li, D. W. Shu, J. W. Hu et al., "A multi-area Thevenin equivalent based multi-rate co-simulation for control design of practical LCC HVDC system," International Journal of Electrical Power \& Energy Systems, vol. 115, 2020.

[17] M. Mankour and B. Sami, "Mitigation of commutation failure method in LCC converter based on HVDC systems by mean of modeling and simulation," Journal of Ambient Intelligence and Humanized Computing, vol. 16, 2020.

[18] Z. H. Wei, W. L. Fang, and J. Liu, "A criterion for accurate identification of commutation failure in HVDC systems," Electric Power Systems Research, vol. 184, no. 12, 2020.

[19] Q. Wang, C. Zhang, X. Wu, and Y. Tang, "Commutation failure prediction method considering commutation voltage distortion and DC current variation," IEEE Access, vol. 7, pp. 96531-96539, 2019.

[20] C. Xiao, W. Han, J. X. Ouyang et al., "Ride-through control method for the continuous commutation failures of HVDC systems based on DC emergency power control," Energies, vol. 12, no. 21, 2019.

[21] Y. Shao and Y. Tang, "Fast evaluation of commutation failure risk in multi-infeed HVDC systems," IEEE Transactions on Power Systems, vol. 33, no. 1, pp. 646-653, 2018.

[22] C. Guo, B. Liu, and C. Zhao, "A DC chopper Topology to mitigate commutation failure of line commutated converter based high voltage direct current transmission," Journal of Modern Power Systems and Clean Energy, vol. 8, no. 2, pp. 345-355, 2020.

[23] T. Li, T. Zhao, M. C. Lv et al., "The mechanism and solution of the anomalous commutation failure of multi-infeed HVDC transmission systems," International Journal of Electrical Power \& Energy Systems, vol. 114, Article ID 105400, 2020.

[24] Z. Wei, Y. Yuan, X. Lei, H. Wang, G. Sun, and Y. Sun, "Directcurrent predictive control strategy for inhibiting commutation failure in HVDC converter," IEEE Transactions on Power Systems, vol. 29, no. 5, pp. 2409-2417, 2014.

[25] S. Mirsaeidi and X. Dong, "An integrated control and protection scheme to inhibit blackouts caused by cascading fault in large-scale hybrid AC/DC power grids," IEEE Transactions on Power Electronics, vol. 34, no. 8, pp. 7278-7291, 2019.

[26] A. Q. Al-Shetwi, M. Z. Sujod, and F. Blaabjerg, "Low voltage ride-through capability control for single-stage inverter-based grid-connected photovoltaic power plant," Solar Energy, vol. 159, pp. 665-681, 2018.

[27] A. Arshad and M. Lehtonen, "A comprehensive voltage control strategy with voltage flicker compensation for highly
PV penetrated distribution networks," Electric Power Systems Research, vol. 172, pp. 105-113, 2019.

[28] M. N. Bhukya, V. R. Kota, and S. R. Depuru, "A simple, efficient, and novel standalone photovoltaic inverter configuration with reduced harmonic distortion," IEEE Access, vol. 7, pp. 43831-43845, 2019.

[29] R. Teodorescu, F. Blaabjerg, M. Liserre, and P. C. Loh, "Proportional-resonant controllers and filters for grid-connected voltage-source converters," IEE Proceedings-Electric Power Applications, vol. 153, no. 5, pp. 750-762, 2006.

[30] M. Castilla, J. Miret, J. L. Sosa, J. Matas, and L. G. de Vicuña, "Grid-fault control scheme for three-phase photovoltaic inverters with adjustable power quality characteristics," IEEE Transactions on Power Electronics, vol. 25, no. 12, pp. 29302940, 2010.

[31] Y. Yang, H. Wang, and F. Blaabjerg, "Reactive power injection strategies for single-phase photovoltaic systems considering grid requirements," IEEE Transactions on Industry Applications, vol. 50, no. 6, pp. 4065-4076, 2014.

[32] L. B. Wu, Z. M. Zhao, and J. Z. Liu, "A single-stage threephase grid-connected photovoltaic system with modified MPPT method and reactive power compensation," IEEE Transactions on Energy Conversion, vol. 22, no. 4, pp. 881-886, 2007.

[33] M. Karimi-Ghartemani, M. Mojiri, A. Safaee et al., "A new phase-locked loop system for three-phase applications," IEEE Transactions on Power Electronics, vol. 28, no. 3, pp. 12081218, 2013.

[34] O. S. Elazab, M. Debouza, H. M. Hasanien, S. M. Muyeen, and A. Al-Durra, "Salp swarm algorithm-based optimal control scheme for LVRT capability improvement of grid-connected photovoltaic power plants: design and experimental validation," IET Renewable Power Generation, vol. 14, no. 4, pp. 591-599, 2020.

[35] M. Durairasan and D. Balasubramanian, “An efficient control strategy for optimal power flow management from a renewable energy source to a generalized three-phase microgrid system: a hybrid squirrel search algorithm with whale optimization algorithm approach," Transactions of the Institute of Measurement and Control, vol. 42, no. 11, pp. 1960-1976, 2020.

[36] A. Q. Al-Shetwi and M. Z. Sujod, "Modeling and control of grid-connected photovoltaic power plant with fault ridethrough capability," Journal of Solar Energy Engineering, vol. 140, no. 2, 2018.

[37] R. K. Varma and H. Maleki, "PV solar system control as STATCOM (PV-STATCOM) for power oscillation damping," IEEE Transactions on Sustainable Energy, vol. 10, no. 4, pp. 1793-1803, 2019.

[38] O. A. Ajeigbe, J. L. Munda, and Y. Hamam, "Towards maximising the integration of renewable energy hybrid distributed generations for small signal stability enhancement: a review," International Journal of Energy Research, vol. 44, no. 4, pp. 2379-2425, 2020.

[39] I. Abadlia, M. Adjabi, and H. Bouzeria, "Sliding mode based power control of grid-connected photovoltaic-hydrogen hybrid system," International Journal of Hydrogen Energy, vol. 42, no. 7, pp. 28171-28182, 2017.

[40] N. Stringer, N. Haghdadi, A. Bruce et al., "Observed behavior of distributed photovoltaic systems during major voltage disturbances and implications for power system security," Applied Energy, vol. 260, no. 14, 2020.

[41] R. Zhang and B. Hredzak, "Nonlinear sliding mode and distributed control of battery energy storage and photovoltaic 
systems in AC microgrids with communication delays," IEEE Transactions on Industrial Informatics, vol. 15, no. 9, pp. 5149-5160, 2019.

[42] Y. C. Zhou, J. M. Liu, Y. G. Li et al., "A gain scheduling widearea damping controller for the efficient integration of photovoltaic plant," IEEE Transactions on Power Systems, vol. 34, no. 3, pp. 1703-1715, 2020.

[43] A. Q. Al-Shetwi, M. Z. Sujod, F. Blaabjerg, and Y. Yang, "Fault ride-through control of grid-connected photovoltaic power plants: a review," Solar Energy, vol. 180, pp. 340-350, 2019.

[44] E. Rahimi, A. M. Gole, J. B. Davies, I. T. Fernando, and K. L. Kent, "Commutation failure analysis in multi-infeed HVDC systems," IEEE Transactions on Power Delivery, vol. 26, no. 1, pp. 378-384, 2011.

[45] L. L. Li, Z. F. Liu, C. H. Wang et al., "The open-circuit voltage characteristic and state of charge estimation for lithium-ion batteries based on an improved estimation algorithm," Journal of Testing and Evaluation, vol. 48, no. 2, pp. 17121730, 2020.

[46] R. Razi, H. Iman-Eini, M. Hamzeh, and S. Bacha, "A novel extended impedance-power droop for accurate active and reactive power sharing in a multi-bus microgrid with complex impedances," IEEE Transactions on Smart Grid, vol. 11, no. 5, pp. 3795-3804, 2020.

[47] L.-L. Li, Y.-W. Liu, M.-L. Tseng, G.-Q. Lin, and M. H. Ali, "Reducing environmental pollution and fuel consumption using optimization algorithm to develop combined cooling heating and power system operation strategies," Journal of Cleaner Production, vol. 247, Article ID 119082, 2020.

[48] X. Hu, Z.-W. Liu, G. Wen, X. Yu, and C. Liu, "Voltage control for distribution networks via coordinated regulation of active and reactive power of DGs," IEEE Transactions on Smart Grid, vol. 11, no. 5, pp. 4017-4031, 2020.

[49] Y. Tang, F. Li, Q. Wang, B. Chen, Y.-l. Jiang, and X.-j. Guo, "Power stability analysis of UHVDC systems hierarchically connected to AC systems," Electric Power Systems Research, vol. 163, pp. 715-724, 2018.

[50] A. Aamir, L. Qiao, C. Y. Guo et al., "Impact of synchronous condenser on the dynamic behavior of LCC-based UHVDC system hierarchically connected to AC system," CSEE Journal of Power and Energy Systems, vol. 5, no. 2, pp. 190-198, 2019. 